\title{
O 'não lugar' das Organizações Sociais e a busca dos gestores pela eficiência no SUS
}

The 'no place' of Social Organizations and managers' search for efficiency in SUS

Tânia Regina Krüger ${ }^{1}$ Cyntia de Oliveira Nogueira Bastos ${ }^{2}$

\section{Resumo}

O objetivo deste texto é identificar e analisar como as Organizações Sociais (OS) na gestão dos serviços do Sistema Único de Saúde (SUS) se apresentam nos municípios de Santa Catarina, por meio de estudo dos Planos Municipais de Saúde no quadriênio 2018-2021 e nas leis que Instituem o Programa Municipal de Incentivo às Organizações Sociais. Trata-se de uma pesquisa exploratória, por meio de estudo bibliográfico e documental, que contemplou 23 municípios distribuídos entre as oito macrorregiões de Santa Catarina. $\mathrm{Na}$ primeira parte são apresentadas as tendências teórico-políticas e técnicas em relação ao SUS e modelos de gestão, problematizando os argumentos da retórica neoliberal e o ocultamento da natureza privada das OS. Na segunda parte, os resultados da pesquisa documental evidenciam que Planos

${ }^{1}$ Possui graduação em Serviço Social pela Universidade Federal de Santa Catarina (1990), mestrado em Educação e Cultura pela Universidade do Estado de Santa Catarina (1998) e doutorado em Serviço Social pela Universidade Federal de Pernambuco (2005). Pós-doutoramento no Centro de Estudos Sociais- CES - Universidade de Coimbra. (2018). Professora na Universidade Federal de Santa Catarina (UFSC), E-

Municipais de Saúde tornam invisíveis as OS, enquanto em 10 municípios há leis que instituem o Programa das Organizações Sociais. Os Planos, de modo geral, usam uma linguagem genérica que não nos permite interpretar se estão em conformidade com os fundamentos do SUS. Apenas um município faz a defesa franca da gestão pública do SUS. A insuficiência de financiamento é o problema pontado pela maioria como o principal desafio da gestão e a narrativa técnico-gerencial da eficiência é referência para descrição dos problemas e das prioridades.

Descritores: SUS, Gestão em saúde, Organização Social.

\footnotetext{
Abstract

The objective of this text is to identify and analyze how Social Organizations (SO) in the management of services of the Unified Health

mail:tania.kruger@ufsc.br/ https://orcid.org/0000-0002-7122$\underline{6088}$.

${ }^{2}$ Estudante em Serviço Social na Universidade Federal de Santa Catarina (UFSC). Bolsista na Universidade Federal de Santa Catarina (UFSC). E-mail: cyntiaonb@gmail.com https://orcid.org/0000-0002-1243-5015
} 
System (SUS) are presented in the municipalities of Santa Catarina, through the study of the Municipal Health Plans in the 2018-2021 quadrennium and the laws that establish the Municipal Incentive Program to Social Organizations. This is an exploratory research through bibliographic and documentary study, which included 23 municipalities distributed among the eight macro-regions of Santa Catarina. The first part presents the theoretical-political and technical trends in relation to SUS and management models, problematizing the arguments of neoliberal rhetoric and the hiding of the private nature of SO. In the second part, the results of the documentary research show that Municipal Health Plans make SO invisible, while in 10 municipalities there are laws that establish the Social Organizations Program. Plans generally use a generic language that does not really allow us to interpret whether they are in accordance with the fundamentals of SUS. Only one municipality makes a frank defense of SUS public management. Insufficient funding is the problem pointed out by most as the main management challenge and the technical-managerial narrative of efficiency is a reference for describing problems and priorities.

Keywords: SUS, Health management, Social Organization.

\section{Resumen}

El objetivo de este texto es identificar y analizar cómo se presentan las Organizaciones
Sociales (OS) en la gestión de los servicios del Sistema Único de Salud (SUS) en los municipios de Santa Catarina, a través del estudio de los Planes de Salud Municipales en el cuatrienio 2018-2021 y las leyes que establecen el Programa de Incentivos Municipales a las Organizaciones Sociales. Esta es una investigación exploratoria a través del estudio bibliográfico y documental, que incluyó 23 municipios distribuidos entre los ocho macrorregiones de Santa Catarina. La primera parte presenta las tendencias teóricopolíticas y técnicas en relación con el SUS y los modelos de gestión, problematizando los argumentos de la retórica neoliberal y la ocultación de la naturaleza privada de las OS. En la segunda parte, los resultados de la investigación documental muestran que los Planes de Salud Municipales hacen invisibles a las OS, mientras que en 10 municipios existen leyes que establecen el Programa de Organizaciones Sociales. Los planes generalmente usan un lenguaje muy genérico, que en realidad no nos permite interpretar si funcionan de acuerdo con los fundamentos del SUS. Solo un municipio defiende francamente la gestión pública del SUS. La falta de fondos es el problema señalado por la mayoría como el principal desafío de gestión y la narrativa técnico-gerencial de la eficiencia es una referencia para describir problemas y prioridades.

Descriptores: SUS, Gestión de la salud, Organizaciones Sociales. 


\section{Introdução}

O aprofundamento da fratura entre economia e política, que leva de maneira continuada a economia a se manifestar como não política e, por sua vez, a política a se manifestar como não econômica, supõe um esgarçamento das relações sociais que as constituem. É um quadro difuso fundamentado no ideário liberal que parece conformar uma sociedade sem interesses, sem relações de poder, e também obscurece a fronteira entre capital e trabalho ${ }^{(1)}$.

Quando se analisa a particularidade da política pública de saúde brasileira, essa fratura entre economia e política também tem uma significativa expressão. O Sistema Único de Saúde (SUS) vem sendo despolitizado a tal ponto que chega a parecer não político, reduzido a uma técnica de eficiência e efetividade, de controle de custos e resultados, com novo modelo de remuneração, mediado por carteira de serviços ou procedimentos operacionais padrão. O seu lado político - que se fundamenta na saúde como direito da população e como obrigação do Estado de prestar serviço universal e integral, que reconhece a determinação social da saúde e da doença - é desconsiderado e ocultado. Tais referências políticas do campo democráticopopular vem sendo descontruídas pela retórica liberal-tecnicista e fraturando de vez sua relação com a economia ${ }^{(1)}$.

O fundo público, que absorve grande parte dos recursos do trabalho e irrisória parcela do capital e do patrimônio dos ricos, é destituído de sua função pública e política, da sua função de realizar serviços públicos e coletivos, e é colocado a serviço da amortização da dívida pública e serve de subsídio ou empréstimo para bancos e grandes empresas. Inclusive na forma de empréstimo vem viabilizando desde os anos de 1990 a privatização de instituições públicas do país. Desse modo, o resultado é uma carga tributária regressiva, significando que o fundo público do Estado brasileiro é financiado, em grande parte, pelas classes de menor poder aquisitivo e pelos trabalhadores- Esses são alguns elementos que nos mostram como, no cotidiano, economia e política são colocados em lados opostos e a fronteira entre público e privado, que nunca teve limites claros, perde cada vez mais seus contornos.

No caso da gestão do SUS, as Organizações Sociais (OS), enquanto uma terceira forma de propriedade entre a privada e a estatal, criada pela Reforma do Estado na década de $1990^{(2)}$, vem borrando a fronteira entre público e privado, entre economia e política, ao serem contratadas pelo poder público para fazer a gestão dos serviços SUS. Nem públicas, nem privadas, situadas numa espécie de 'não lugar', as OS no SUS escondem a natureza privada da instituição, acessam o recurso público, para formalmente cumprirem uma função pública ${ }^{(3)}$.

A condição já anunciada no texto constitucional de que "a assistência à saúde é livre à iniciativa privada"(4) e a prática do Ministério da Saúde de se subordinar aos 
ministérios da área econômica para as decisões sobre o financiamento do SUS facilitou, nesses 30 anos, a sujeição das necessidades de saúde aos interesses privados e do mercado. Nessas décadas, o privado foi invadindo os fundamentos legais e políticos do SUS por meio de uma série de figuras e entes jurídicos da contrarreforma do Estado e as OS representam uma das suas grandes expressões. Essa invasão privada no DNA do SUS, no caso das OS, vem sendo permeada por uma retórica de apelo de bom serviço, de parceria e eficiência que, de fato, esconde o caráter privado da entidade, critica a gestão do Estado, ao mesmo tempo que exige dele ser bom repassador de recursos. Por isso, avaliamos que as OS ocupam no SUS esse 'não lugar', não se apresentam efetivamente como empresas privadas e, de igual modo, não aceitam ser caracterizadas como serviço público. Algumas frases que exemplificam essa retórica: "Terceiro setor, parceiro imprescindível do setor público"; "Hora de aprender com os erros e ampliar os acertos"; "Em busca de soluções estruturais para a saúde"; "Transparência é o nome do jogo"; "Um longo e bom caminho para avançar"; "Um antídoto contra a desconfiança"; "O interesse público como objetivo comum"(5).

Tendo como pano de fundo essa compreensão do contexto no qual emergem as $\mathrm{OS}^{(2)}$ enquanto empresas privadas que se habilitam para fazer a gestão dos serviços do SUS, o objetivo do presente texto é identificar e analisar como as OS na gestão dos serviços do SUS se apresentam nos municípios de Santa Catarina, por meio de estudo dos Planos Municipais Plurianuais de Saúde no quadriênio 2018-2021 e das leis municipais que instituem o Programa Municipal de Incentivo às Organizações Sociais.

Tal intenção é uma parte do contínuo esforço de compreender como as OS se apresentam nos instrumentos de gestão da política de saúde. Em estudo anterior sobre os Planos Estaduais Plurianuais de Saúde dos quadriênios de 2012-2015 e 2016-2019 de onze Estados brasileiros, evidenciou-se que poucos Planos fazem referências explícitas aos serviços que estavam sob gestão de OS, no entanto, a maioria propõe a adoção da gestão dos serviços por meio de OS e estratégias que se vinculam a parceria público-privado ${ }^{(6)}$.

Outra justificativa para este estudo se deve ao fato de serem as OS o tipo de administrador que mais avança na gestão dos estabelecimentos públicos de saúde no país. Em 2018, segundo o $\operatorname{IBGE}^{(7)}$, dentre as 27 Unidades da Federação, 15 declararam ter estabelecimentos sob gestão de OS; apenas 7 declararam não ter estabelecimentos de saúde administrados por terceiros, que são: Rondônia, Roraima, Tocantins, Rio Grande do Norte, Alagoas, Sergipe e Minas Gerais.

A mesma pesquisa do $\mathrm{IBGE}^{(7)}$ revelou que nos municípios brasileiros 13,2\% dos estabelecimentos de saúde eram administrados por terceiros em 2018, e em 2014 esse percentual era de 10,6\%. Dos estabelecimentos sob responsabilidade municipal administrados 
por terceiros, $58,3 \%$ eram administrados por OS; $15,0 \%$ por empresas privadas; $11,0 \%$ por consórcios públicos; e 9,4\% por Fundações.

Esse crescimento das OS na saúde pública tem sido um dos assuntos mais noticiados nos últimos anos, em todas as mídias, fazendo parte das manchetes nacionais e sendo objeto de investigações da Polícia Civil e Federal, do Ministérios Públicos e dos Tribunais de Contas. As irregularidades são amplamente noticiadas ${ }^{(8-9)}$. Por outro lado, há um fortalecimento dessa modalidade de gestão com a crescente qualificação como OS de entidades que celebram contratos de gestão em várias unidades da federação, permitindo a solidificação do Instituto Brasileiro das Organizações Sociais de Saúde (IBROSS). Esse Instituto tem feito parcerias com o Conselho Nacional de Secretários de Saúde (Conass) e o Tribunal de Contas da União (TCU), como ficou explícito no Seminário de Boas Práticas na Gestão de Parceria com o Terceiro Setor na Saúde ${ }^{(5)}$.

$\mathrm{Na}$ sequência, o presente texto se estrutura nos seguintes itens: primeiro a metodologia da pesquisa, seguido de reflexões e análises sobre as tendências teórico-políticas e técnicas em relação ao SUS e modelos de Quadro1 - Relação das Macrorregiões e Municípios - Santa Catarina

\begin{tabular}{|l|l|l|}
\hline Macrorregiões & $\mathbf{N}^{\mathbf{0}}$ Municípios & Municípios contemplados no estudo \\
\hline Grande Florianópolis & 13 & Florianópolis, São José e Palhoça \\
\hline Litoral Norte & 42 & $\begin{array}{l}\text { Joinville, Jaraguá do Sul, Blumenau, Brusque, } \\
\text { Itajaí e Balneário Camboriú }\end{array}$ \\
\hline Alto Vale do Itajaí & 31 & Rio do Sul \\
\hline Litoral Sul & 47 & Criciúma e Tubarão \\
\hline Planalto Serrano & 18 & Lages \\
\hline
\end{tabular}




\begin{tabular}{|l|l|l|}
\hline Planalto Norte & 13 & São Bento do Sul e Mafra \\
\hline Meio Oeste & 55 & $\begin{array}{l}\text { Joaçaba, Caçador, Curitibanos, Concórdia e } \\
\text { Videira }\end{array}$ \\
\hline Oeste & 76 & Chapecó, São Miguel do Oeste e Xanxerê \\
\hline Total & $\mathbf{2 9 5}$ & $\mathbf{2 3}$ \\
\hline
\end{tabular}

Fonte: SANTA CATARINA. Plano de Desenvolvimento de Santa Catarina 2030. 2018. P. 113. Disponível em http://www.spg.sc.gov.br/visualizar-biblioteca/acoes/plano-catarinense-de-desenvolvimento/1162-plano-sc-2030versao-final/file. Consultado em 18 abr. 2019

Mapa 1 - Estado de Santa Catarina com destaque e população estimada em $2019^{(7)}$ dos 23 municípios que tiveram os Planos Municipais de Saúde do quadriênio de 2018-2021 contemplados no estudo.

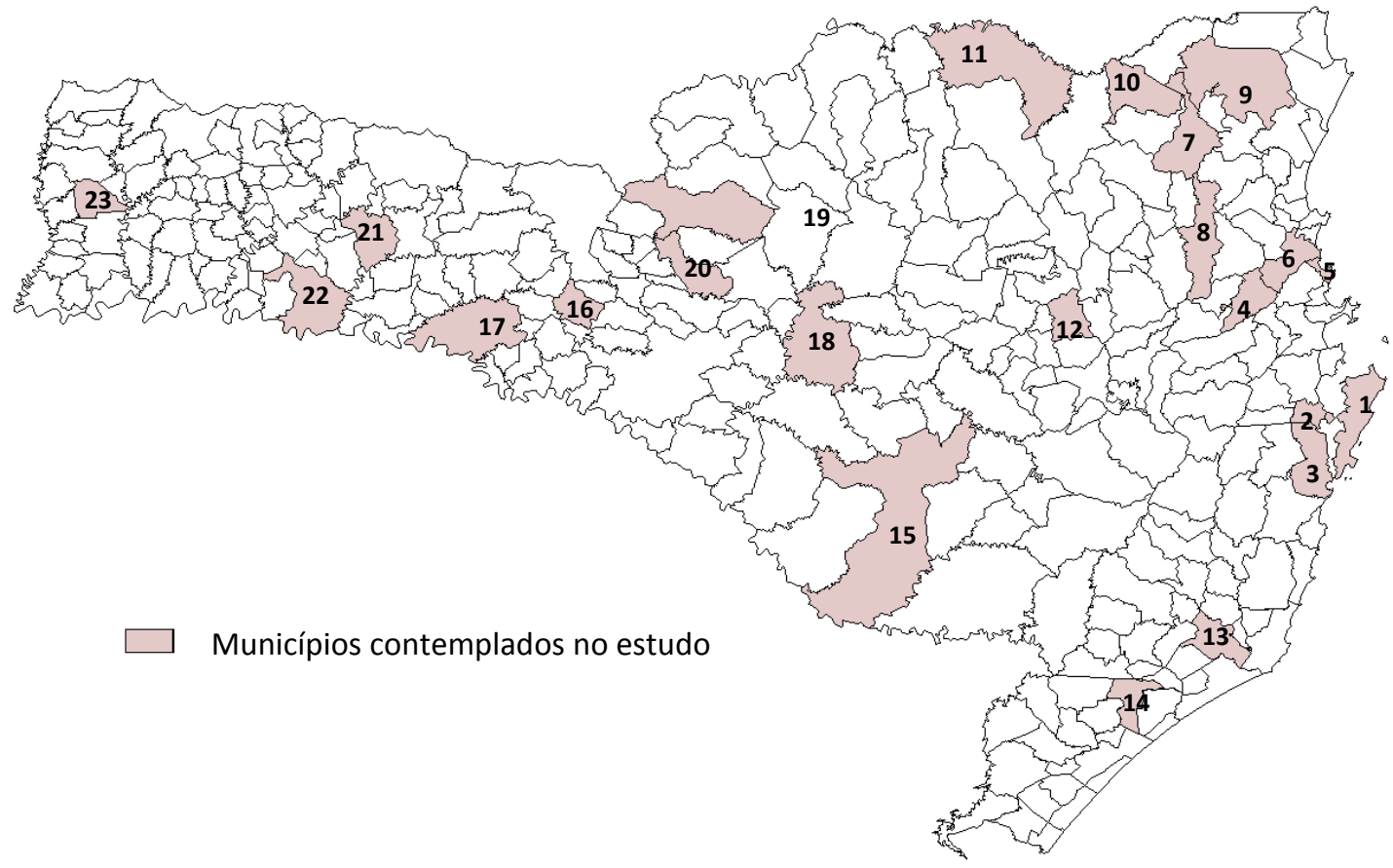

Fonte: Elaboração a partir do Tabwin - Tab para Windows. Versão disponibilizada pelo DATASUS. Acesso http://www2.datasus.gov.br/DATASUS/index.php?area=060805\&item=3

\begin{tabular}{|l|l|l|l|l|l|l|l|l|l|}
\hline $\mathbf{N}^{\mathbf{0}}$ & & Cidade & Pop. & $\mathbf{N}^{\mathbf{0}}$ & Cidade & Pop. & $\mathbf{N}^{\mathbf{0}}$ & Cidade & Pop. \\
\hline 1 & & Florianópolis & 500.973 & $\mathbf{9}$ & Joinville & 590.466 & $\mathbf{1 7}$ & Concórdia & 74.641 \\
\hline $\mathbf{2}$ & & São José & 246.586 & $\mathbf{1 0}$ & S. Bento do Sul & 84.507 & $\mathbf{1 8}$ & Curitibanos & 39.745 \\
\hline $\mathbf{3}$ & & Palhoça & 171.797 & $\mathbf{1 1}$ & Mafra & 56.292 & $\mathbf{1 9}$ & Caçador & 78.595 \\
\hline $\mathbf{4}$ & & Brusque & 134.723 & $\mathbf{1 2}$ & Rio do Sul & 71.061 & $\mathbf{2 0}$ & Videira & 53.065 \\
\hline $\mathbf{5}$ & & Bal. Camboriú & 142.295 & $\mathbf{1 3}$ & Tubarão & 105.686 & $\mathbf{2 1}$ & Xanxerê & 50.982 \\
\hline $\mathbf{6}$ & & Itajaí & 219.536 & $\mathbf{1 4}$ & Criciúma & 215.186 & $\mathbf{2 2}$ & Chapecó & 220.367 \\
\hline $\mathbf{7}$ & & Jaraguá do Sul & 177.697 & $\mathbf{1 5}$ & Lages & 157.544 & $\mathbf{2 3}$ & S. Miguel do Oeste & 40.482 \\
\hline $\mathbf{8}$ & & Blumenau & 357.199 & $\mathbf{1 6}$ & Joaçaba & 30.118 & & & \\
\hline
\end{tabular}


Fonte: IBGE. Estimativas da população residente nos municípios brasileiros com data de referência em $1^{\circ}$ de julho de 2019. Diretoria de Pesquisas - DPE - Coordenação de População e Indicadores Sociais - COPIS. Disponível https://agenciadenoticias.ibge.gov.br/media/com_mediaibge/arquivos/42ff76cf13a382a709c1ba14214b8612.pdf. Consultado em 11 nov. 2019.

Após o estudo da literatura que aponta as diferentes tendências teórico-políticas do SUS, sua conjuntura e modelos de gestão de saúde no Brasil, iniciou-se a busca pelos Planos Municipais de Saúde de cada município nas páginas eletrônicas das Secretarias Municipais de Saúde. Os Planos de Balneário Camboriú, Brusque, Criciúma e Rio do Sul não estavam on-line e foram obtidos via contato por e-mail ou telefone com as respectivas Secretaria de Saúde.

A pesquisa das leis municipais que instituem o Programa Municipal de Incentivo às Organizações Sociais se deu por busca com os termos 'Organizações Sociais' e 'Organização Social' no Portal de Leis Municipais ${ }^{(11)}$.

Inicialmente, os Planos Municipais de Saúde foram contextualizados considerando os sujeitos participantes da elaboração, a metodologia de construção, aprovação pelos Conselhos Municipais de Saúde e sua estrutura com base no que prevê as diretrizes do planejamento no âmbito do SUS. Posteriormente, iniciou-se a sistematização de dados relevantes para a pesquisa, tais como: as referências legais da construção dos Planos; análise situacional e/ou diagnóstico de cada município; e, por fim, a identificação das prioridades em relação aos modelos de gestão, aí contidos eixos, diretrizes, objetivos, metas e indicadores. Foram também construídas planilhas com os achados em cada Plano, com vistas a possibilitar comparações, análises quantitativas e qualitativas, e identificar particularidades.

Este artigo é o resultado parcial do projeto de pesquisa guarda-chuva intitulado "Saúde e Serviço Social: planejamento, gestão, participação e exercício profissional" (segunda edição), com realização prevista para o período de 01/03/2019 a 28/02/2023, registrado no sistema SIGPEX UFSC com o seguinte protocolo: 201901764. A pesquisa sobre as “Organizações Sociais na gestão dos serviços do SUS: como se apresentam nos Planos Municipais Plurianuais de Saúde 2018-2021 de Santa Catarina" foi contemplada com bolsa PIBIC-Af/CNPq - BIPI/UFSC, 2019/2021, Edital Propesq 01/2019. O estudo também é continuidade do projeto de iniciação científica desenvolvido nos períodos de 2015/2016, 2016/2017, que identificou como os modelos de gestão dos serviços do SUS por Organizações Sociais se apresentam nos Planos Estaduais Plurianuais de Saúde - PES dos quadriênios 2012-2015 e 2016-2019 de 11 estados, a saber: Amazonas, Pará, Bahia, Paraíba, Pernambuco, Distrito Federal, Goiás, 
Rio de Janeiro, São Paulo, Rio Grande do Sul e Santa Catarina ${ }^{(6)}$.

\section{Revisão de literatura}

O neoliberalismo, revestido de uma retórica liberal-social, emergiu como uma alternativa de poder extremamente vigorosa contra o Estado intervencionista e de bemestar. Para tanto, adotou uma série de estratégias políticas, econômicas e jurídicas orientadas para encontrar uma saída da crise dentro do próprio capitalismo. As práticas técnicas e políticas neoliberais de alterar as cadeias produtivas, reformar estruturalmente $\mathrm{o}$ Estado, realizar privatizações e abertura econômica para atrair investimentos internacionais expressam e sintetizam um projeto de reforma ideológica da sociedade para a construção e a difusão de um novo senso comum que fornece coerência, sentido e uma pretensa legitimidade às reformas. Segundo Gentilli $^{(12)}$ :

O êxito cultural mediante a imposição de um novo discurso que explica a crise e oferece um marco geral de respostas e estratégias para sair dela se expressa na capacidade que os neoliberais tiveram de impor suas verdades como aquelas que devem ser defendidas por qualquer pessoa medianamente sensata e responsável. Os governos neoliberais não só transformam materialmente a realidade econômica, política, jurídica e social, também conseguem que essa transformação seja aceita como a única saída possível (ainda que, às vezes, dolorosa) para a crise.

Os anos de vida do paradigma neoliberal promoveram privatização; ideia de superioridade do livre mercado como mecanismo de alocação eficiente de recursos; individualismo de vida e de consumo; crença nos valores individuais e em soluções de mercado; liberdade, em detrimento da igualdade; questionamento dos direitos e políticas sociais; descrédito na capacidade de gerenciamento do Estado ${ }^{(13)}$. Para as autoras, no discurso neoliberal a austeridade é para justificar a moderação no crescimento dos salários e da oferta de bens e serviços públicos, porque evitaria prejuízo à poupança dos empresários, que é necessária para a geração de empregos e para o bem-estar futuro dos consumidores. A crítica não se emprega, entretanto, a moderação dos lucros, a monopolização empresarial e especulação financeira, e a que, ao adotar essas políticas se defende os empresários e não os trabalhadores. Assim, a austeridade proposta não é a dos que consomem mais (os ricos), mas a dos trabalhadores que dependem de serviços públicos, o que aumenta a injustiça social.

Para Siqueira e Borges ${ }^{(3)}$, as décadas de neoliberalismo de fato comprovam que essa política tem aumentado os gastos públicos e o intervencionismo do Estado em favor da classe dominante. O lema "navegar em vez de remar" (desburocratizar e diminuir o governo grande) está sendo, de forma crescente, fonte de 
inspiração para a gestão pública gerencial do Estado brasileiro. $\mathrm{Na}$ era da informação, o setor público deve mudar sua missão, incentivos, prestação de contas, estrutura de poder e de cultura. Dessa forma, para navegar basta controlar, direcionar e orientar, já que remar se refere ao Estado intervencionista que presta os serviços diretamente, faz a gestão das instituições públicas e zela pelos bens nacionais e por princípios coletivos de políticas sociais e econômicas.

Portanto, foi nesse ambiente político e técnico de reinvenção do governo e da gestão pública que emergiram as OS, impulsionando a terceirização e a privatização do setor de saúde no Brasil. De forma mais acentuada, o mercado e a sociedade civil passaram a fazer parte do SUS no momento em que integrantes dos governos defendem as OS como uma forma interessante, por agilizar o atendimento à população, quando a causa diagnosticada é a burocracia do sistema $^{(3)}$. São novos arranjos institucionais e de gestão, novos entes jurídicos (mix público-privado) que a dimensão institucional-administrativa neoliberal elabora em nome da modernização, flexibilidade, economia e eficiência.

As OS foram regulamentadas no Brasil $^{(2)}$ em meio ao clima ideológico de fortes críticas às políticas do Estado de direito que vêm se afirmando desde o início da década de 1990, com a divulgação das ideias de que o Estado não é competente, é lento, seus trâmites burocráticos são morosos, ineficientes, sofre ingerências políticas, e que todas essas qualidades e virtudes se encontram na gestão dos serviços privados. Esse clima ideológico se solidificou na avaliação de Nogueira ${ }^{(14)}$, quando as forças neoliberais vieram "a público proclamar que o Estado simbolizava o atraso indesejável e a constituição da modernidade por todos almejada dependia da negação do Estado".

Nesse contexto, o mix público-privado, o mercado e a sociedade civil são os novos sujeitos institucionais que passam a formar as OS, sob o controle do Estado. São caracterizadas como associações civis sem fins lucrativos que não são de propriedade de nenhum indivíduo ou grupo, que estão orientadas diretamente para o atendimento do interesse público ${ }^{(4)}$ e, portanto, parece que se vinculam diretamente a transparência, coletividade, gestão eficiente e controle de custos e resultados. A titulação 'sem fins lucrativos' quase chega a assegurar sua idoneidade, parece que lhe dá maior legitimidade social e oculta vinculação mercantil. Segundo Siqueira e Borges ${ }^{(3)}$ : "o 'não lugar', nem público e nem privado, lhe dá a aparência de não possuir o ônus ou o bônus de não ser estatal e não ser uma organização privada. $\mathrm{Ou}$ seja, esse 'não lugar', acaba por estabelecer um espaço que pode beneficiar-se de ambos os estatutos jurídicos".

Esse 'não lugar', nem público e nem privado, segundo Fontes ${ }^{(15)}$, tem por detrás uma enorme variedade de entidades, desde associações efetivamente populares, grandes 
universidades e hospitais, até semiempresas como as OS da saúde. Incluem entidades voltadas para a própria organização das burguesias, assim como agem para transformar a gestão pública em privada. Traduzem o 'ativismo' empresarial para domesticar populações em períodos formalmente democráticos ou para justificar ações de resolução de crises econômicas e sociais. E, adverte a autora, nos últimos anos a atuação de tais entidades contribuiu para deslegitimar as opções eleitorais populares ao encaminhar soluções empresariais pré-preparadas para a atuação política dos gestores em municípios, estados e governo federal.

As OS seguramente fazem parte do amplo complexo econômico industrial da saúde. Seus técnicos possuem conhecimento especializado sobre tecnologias diversas, medicamentos, patentes e laboratórios globalizados, distribuição dos serviços nos equipamentos e na rede de serviços. Desde a década de 1990 as Organizações Sociais ganharam a especificidade de OS da saúde, focando suas ações nessa área, e ampliaram a expertise na gestão dos serviços da saúde pública por meio dos contratos de gestão com os gestores estaduais e municipais. Desse modo, as OS formaram um amplo grupo, sendo influenciadoras e competitivas no mercado da área de saúde. Os grupos empresariais médicos, de equipamentos e as entidades filantrópicas atendem aos editais de qualificação de Organizações Sociais da saúde chamados pelos estados e munícipios (ou de certa forma por eles impulsionados) para futura operacionalização da gestão e execução das ações e serviços de saúde ${ }^{(3)}$.

A administração predominante no complexo econômico industrial da saúde é gerencial e as OS, ao fazerem a gestão dos serviços nesse âmbito, se tornaram uma estratégia para o distanciamento da execução estatal, fragilizando o vínculo empregatício dos seus trabalhadores e fraturando sua identidade e organização coletiva (p.ex. os servidores estaduais de saúde perdem sua identidade, pois cada unidade de saúde com gestão de uma OS constrói seu tipo de vínculo, seu plano de cargos e salários). As OS podem contratar trabalhadores sem concurso público, serviços de empresas médicas, de laboratórios, consultorias, pessoas jurídicas individuais, sem passar pela obrigatória lei de licitações do serviço público. Esse grande leque de ações autônomas das OS passa um falso ideário de que são externas ao aparelho estatal, mas por meio de dispositivos jurídicos sua sobrevivência se deve essencialmente ao recebimento do recurso público. No mercado da saúde, as OS se constituíram e se ampliam apenas por meio do recurso público e, dessa forma, cria-se uma relação de dependência e quase de subordinação do setor público ao privado e a tendência é o expansionismo concentrador (por meios de fusões, novas aquisições) desse grupos para captação de recursos públicos. 


\section{Caracterização dos Planos Municipais de} Saúde 2018-2021

No conjunto, os Planos Municipais Plurianuais de Saúde (PMS) se constituem de grandes documentos em média com 170 páginas, mas oscilam de 19 a 400 laudas. O item da análise situacional toma aproximadamente $70 \%$ do tamanho do documento e exigiu grande esforço da equipe técnica que o coordenou, pois são bastante detalhados. Os Planos seguiram as orientações do sistema de planejamento do SUS para a análise situacional, a formulação de Diretrizes, Objetivos, Ações e Metas quadrienais, contemplando os vários sistemas nacionais de informação para evidenciar as particularidades gerais e locais em termos socioeconômicos, epidemiológicos e estrutura de serviços.

Nos PMS de 2018-2021, os serviços do SUS são apresentados de diferentes maneiras, não havendo uma uniformização da descrição. Alguns Planos descrevem muito mais indicadores socioeconômicos e o perfil de morbimortalidade do que o processo de gestão dos serviços. Ao longo do texto fazem referências às normativas do SUS, mas em alguns parecem ser repetições automáticas. Outros retomam os princípios e competências com citações dos artigos constitucionais e da lei de regulamentação do SUS, destacando-se os municípios de Brusque, Itajaí, Criciúma, Concórdia, Lages e São Bento do Sul. Nesses há uma reafirmação do compromisso público com os princípios do SUS, de oferecer ações integrais e qualificadas em saúde, baseadas na promoção e prevenção em saúde, buscando melhorar a qualidade de vida da população.

Poucos documentos fizeram alguma referência ao contexto do SUS na época de sua elaboração, mas em cinco deles há referências explícitas ao cenário de crise econômica. Número menor se referiu à crise política, ao contingenciamento do orçamento e à queda da arrecadação tributária. Como esses instrumentos de gestão foram elaborados no ano seguinte à Emenda Constitucional $\mathrm{n}^{\circ}$ 95/2016, que instituiu o Novo Regime Fiscal definindo um teto para os gastos públicos e o congelamento pelos próximos 20 anos para as políticas sociais, entre elas a saúde, não encontramos nos PMS uma relação para os problemas de gestão e de financiamento, densamente descritos, com a EC 95/2016. Em grande medida, a crise política, socioeconômica e o conjunto das dificuldades mencionadas foram contextualizadas de forma muito genérica. $\mathrm{O}$ município de Caçador não citou a EC 95/2016, mas no texto evidenciou preocupação com o congelamento por 20 anos. O Plano de Xanxerê reproduz a proposta da $1^{\mathrm{a}}$ Conferência Municipal de Saúde da Mulher de fazer moção pedindo revogação da EC 95/2016, e no Plano de Mafra a EC 95/2016 aparece apenas nas referências.

O PMS de Lages valorizou os serviços de excelência do SUS, e outro que demonstrou, 
na nossa avaliação, uma compreensão otimista e até discutível da conjuntura foi o de Curitibanos: o desenvolvimento econômico atualmente tem uma concepção não só de busca por puro crescimento econômico, mas sim do crescimento aliado ao progresso material e bem-estar da população com redução da pobreza.

\section{PMS 2018-2021 - Diagnóstico em relação ao modelo de gestão dos serviços}

No diagnóstico dos PMS, a insuficiência de financiamento é, certamente, o problema apontado pela maioria como o principal desafio da gestão. Reclama-se das dificuldades de compatibilizar o aumento dos custos (trabalhadores, infraestrutura, tecnologia) com as demandas dos serviços de saúde (transição demográfica, perfil epidemiológico, causas externas de morbidade e mortalidade, dificuldade de acesso aos serviços básicos, de urgência e média e alta complexidade). Referem que há portanto uma incoerência entre a situação epidemiológica e o modelo de atenção. Para a insuficiência de recursos um município aponta como saída individualizada qualificar a equipe de captação de recursos e de projetos. Esse é um exemplo do SUS como sistema único estar perdendo vinculações com os entes da federação e seu caráter de Sistema Único.

A gestão em saúde é um desafio que demanda permanente aperfeiçoamento, tanto dos processos de organização e operação, quanto da eficiência na captação e aplicação de recursos de diferentes naturezas disponíveis. Essa afirmação de Xanxerê é bastante presente nos instrumentos de gestão pesquisados e vem acompanhada do detalhamento dos diversos desafios: atrasos no orçamento do município comprometendo a rede de serviços; demora nos processos licitatórios; insuficiente processo regulatório; capacitação insuficiente sobre assuntos de gestão financeira; precarização da área de planejamento da gestão municipal; baixa resolutividade da atenção; judicialização; descentralização de serviço sem o repasse compatível de recursos; baixa capacidade instalada para assumir os compromissos do Pacto de Gestão; rotatividade dos trabalhadores da saúde na rede; problema na reposição, especialmente médicos; ausência de Planos de Cargos, Carreira e Salários; alto absenteísmo de usuários em consultas e exames; crescimento do número dos usuários totalmente dependentes do SUS; queda nos indicadores dos serviços e indicadores epidemiológicos; fila para cirurgias eletivas e consultas especializadas. São inúmeras constatações que os municípios descrevem e parece que vivem sozinhos nesse conjunto de problemas. Mais uma vez a relação federativa e a organicidade do Sistema Único de Saúde se torna invisível.

Ao relacionar os desafios, alguns munícipios já apontam soluções, sendo as principais eficácia, eficiência e boa gerência na 
aplicação dos recursos disponíveis. Sem tratar propriamente do conceito do gerencialismo neoliberal, os municípios (Joaçaba, Palhoça, São Bento do Sul e Xanxerê) começam a adotar essa linguagem nos documentos.

Sobre a natureza das instituições que prestam os serviços do SUS, a maioria absoluta dos municípios faz uma descrição indiferenciada da rede pública, da privada prestadora de serviços, da conveniada filantrópica e da particular. Nessa indiferenciação entre os setores público e privado que realizam os serviços do SUS, observou-se que as coordenações dos setores dos serviços de algumas Secretarias de Saúde passam a ser nominadas gerências, como identificado no documento de Florianópolis. Nessa lógica, o setor público se aproxima do setor privado no modo de gestão e parece secundarizar as particularidades que são próprias da gestão do serviço público, que deve zelar pela universalidade, igualdade de acesso e necessidades coletivas de serviços. Brusque e Balneário Camboriú foram os municípios que enfatizaram os serviços próprios do SUS, apesar do relato dos serviços contratados.

Nos textos de apresentação dos PMS e dos diagnósticos da situação de saúde dos municípios foram observadas indicações, proposições e sugestões onde eficiência é o termo mais ressaltado. Mas não encontramos indicações claras sobre o conceito de eficiência e de excelência na gestão.
Essa narrativa técnico-gerencial da eficiência para políticas sociais identificada nos PMS 2018-2021 também apareceu nos Planos Estaduais de Saúde de onze estados brasileiros nos quadriênios de 2012-5 e 2016$9^{(6)}$. Tal narrativa, ao centrar-se no controle de custos, resultados, desempenho e produtividade, torna invisíveis as necessidades de saúde e as alarmantes desigualdades em saúde, além de ocultar seu custo econômico para a sociedade. Sem dúvida, aqui não desconsideramos a necessidade de boa coordenação, de não desperdício de recurso público, de compromisso ético e de atendimento com qualidade, mas esses não podem submeter o direito à saúde e a histórica desigualdade do acesso a uma racionalidade de eficiência que se aproxima do cálculo matemático puro.

Contrapondo-se a essa visão tecnicista, foram identificadas outras indicações para superar os desafios que se sustentam e se aproximam dos fundamentos do SUS, quais sejam: superar a visão fragmentada na formulação e organização dos serviços, incorporar o maior conhecimento possível dos problemas de saúde e integrar a área da assistência ao modelo epidemiológico adotado (Brusque); oferecer ações integrais e qualificadas em saúde, baseadas na promoção e prevenção em saúde, rastreamento precoce das doenças, buscando melhorar a qualidade de vida da população (Itajaí); valorizar o trabalho dos profissionais da Atenção Básica (São 
Bento do Sul) e garantir um SUS Público, de Qualidade e Universal, é Necessário a União de Forças, o Caminho é Este, e a Hora é Agora, Somos Fortes, Somos SUS (Lages).

Quanto à gestão por Organização Social, na análise situacional dos serviços foram encontradas diretamente três referências nos PMS 2018-2021. Balneário Camboriú descreve uma experiência de gestão por OS que precisou ser encerrada por serviços inadequados. O município de Mafra descreve

Quadro 2 - Referências que os PES 2018-2021, por município, fazem à gestão por Organização Social na análise situacional dos serviços

\begin{tabular}{|l|l|}
\hline Municípios & Referências que os PMS 2018-2021 fazem à gestão por OS \\
\hline Balneário & $\begin{array}{l}\text { P. } 263 \text { - O Hospital Municipal Ruth Cardoso começou a atender em 2011 } \\
\text { administrado por OS Cruz Vermelha, filial do RS, o qual foi interrompido por } \\
\text { prestação de serviço inadequado em 2012. Desde então o município é o gestor. }\end{array}$ \\
\hline Mafra & $\begin{array}{l}\text { P. } 21 \text { - A Unidade de Pronto Atendimento de Mafra (UPA) foi criada em 21/06/2017, } \\
\text { transferidas as instalações, através do Contrato de Gestão no 001/2017, derivado da } \\
\text { Chamada Pública no 002/17, entre o município de Mafra, representado pelo Fundo } \\
\text { Municipal de Saúde e o Hospital Psiquiátrico Mahatma Gandhi. "Atualmente os } \\
\text { serviços de urgência e emergência de Mafra foram repassados a uma organização } \\
\text { social, cabendo ao município, especificadamente à Secretaria de Saúde, acompanhar } \\
\text { a gestão e intervir quando necessário por intermédio da avaliação e identificação de } \\
\text { inconformidades pela Comissão de Avaliação do Contrato de Gestão [...]" (P.21 -22) }\end{array}$ \\
\hline $\begin{array}{l}\text { Hospital da Criança. gerenciado pela Associação Lenoir Vargas Ferreira, Termo de } \\
\text { Convênio no 232/2009. Não denominado e nem qualificado como OS no âmbito } \\
\text { municipal. O Termo do Convênio de 2009 não foi localizado. Conforme documentos } \\
\text { do Tribunal de Contas do Estado, pelo Decreto no 447, de 17 de julho de 2007, a } \\
\text { Associação foi qualificada como OS. }\end{array}$ \\
\hline Chapecó
\end{tabular}

Fonte: PMS 2018-2021 de Balneário Camboriú, Chapecó e Mafra. Elaboração própria.

Dentre os objetivos, diretrizes, ações e

PMS 2018-2021 - Objetivos, diretrizes e metas em relação ao modelo de gestão que tem uma Unidade de Pronto Atendimento (UPA) com gestão de OS. A terceira é o hospital municipal de Chapecó, que tem sua gestão entregue a uma Organização da Sociedade Civil conforme a Lei Federal n. ${ }^{\circ} 13.019 / 14^{(16)}$, que estabelece o regime jurídico das parcerias entre a administração pública e as organizações da sociedade civil em regime de mútua cooperação. 
inadequada que o PMS reporta nos anos 2011 e 2012, o município renova a intenção de entregar a gestão do hospital a uma OS. O município de Chapecó, que não apresenta a Associação Hospitalar Lenoir Vargas Ferreira como uma OS, menciona apenas que pretende promover a manutenção do Hospital da Criança, conforme Plano Operativo e Termo de Convênio $n^{\circ}$ 232/2009 pautado na Lei Federal no 13.019/2014 ${ }^{(16)}$.

O Plano de Itajaí, ainda que sem mencionar a gestão por OS, apresenta o objetivo de combater toda e qualquer iniciativa que permita a terceirização, inclusive para carreiras relacionadas a atividades-fim, que levaria ao rompimento de todos os direitos das trabalhadoras e dos trabalhadores brasileiros; respeitar na íntegra a Lei 8.080/90, em seu aspecto contra a terceirização, sendo somente possível a utilização de serviços privados de forma complementar. Em outro momento do Plano desse município, a diretriz é aperfeiçoar e qualificar a gestão municipal e o objetivo é defender a eliminação absoluta dos subsídios públicos ao mercado de planos e seguros privados de saúde e de insumos, bem como o aprimoramento da cobrança do ressarcimento ao SUS dos serviços prestados aos usuários da saúde suplementar.

$\mathrm{Na}$ maioria absoluta dos PMS não aparece o termo organização social e nem a defesa franca como Itajaí faz da gestão pública do SUS; no entanto, eles estão recheados de termos para melhorar a qualidade, monitoramento, fortalecimento, acesso qualificado e eficiência dos serviços. Entre as prioridades da gestão, alguns municípios são bem ousados e apresentam a intenção de ser excelência e de ser o melhor sistema público e gratuito de saúde (Florianópolis, Tubarão, São José, Joinville, São Bento do Sul).

Promover o acesso com equidade, acessibilidade, vínculo, adscrição da clientela, compromisso com a qualidade, resolutividade dos serviços, humanização e atendimento das necessidades de saúde foram identificados em 17 PMS (Florianópolis, São José, São Miguel do Oeste, Brusque, Joaçaba, Concórdia, Caçador, Chapecó, Xanxerê, Palhoça, Blumenau, Criciúma, Tubarão, Curitibanos, São Bento do Sul, Mafra, Videira). Esses são temas importantes na estruturação dos serviços do SUS. No entanto, apenas 11 Planos apresentaram reforço aos princípios e competências constitucionais do SUS, bem como comprometimento e qualificação dos serviços do SUS (Florianópolis, São José, Joaçaba, Chapecó, Xanxerê, Curitibanos, São Bento do Sul, Videira, Brusque, Itajaí, São Miguel do Oeste).

Os Planos em geral usam uma linguagem muito genérica, que não nos permite interpretar que estejam, de fato, trabalhando conforme os fundamentos do SUS. No caso de Caçador, propõe-se a consolidar o novo modelo de gestão e instrumentos de relação federativa, com centralidade na garantia de acesso. E nos perguntamos qual novo modelo de gestão? Com todos os dispositivos de normatização e 
regulação do SUS ele não é o modelo de gestão?

Sobre o financiamento e a gestão dos recursos, novamente nos deparamos com uma linguagem genérica, que não se relaciona diretamente com os indicadores, necessidades e desafios apresentados no diagnóstico do PMS e nem as condições que estão determinando a crise e o contingenciamento recente dos recursos. Três municípios (Brusque, Itajaí, Caçador) indicaram financiamento estável, mas este escapa à governança da municipalidade, depende de pactuação e normatização federal, que em grande medida já existe, mas parece insuficiente.

Outro aspecto que fica evidente nos Planos é a preocupação com aprimoramento, inovação e monitoramento da gestão, gestão e controle de resultados, gestão de custo, efetividade na gestão, gestão eficiente de recursos, aumento da eficiência dos serviços e ampliação da oferta de ações de saúde conforme a carteira de serviços. Tal preocupação está presente em 14 dos 23 documentos estudados (Florianópolis, Joinville, Balneário Camboriú, Concórdia, Chapecó, Tubarão, São José, Caçador, Brusque, Blumenau, Criciúma, Curitibanos, Mafra e Palhoça). Os documentos carecem de uma qualificação desses termos em relação às necessidades de saúde e demandas dos serviços; quanto aos indicadores, ao corpo profissional e técnico efetivo, à infraestrutura instalada e potencial, e aos recursos disponibilizados. E cabe voltar à pergunta: eficiência de quê e para quem? Ou podemos relacionar gestão eficiente para aumentar a resolutividade, aumentar a acessibilidade e o atendimento das necessidades de saúde? Mas gestão eficiente não aparece nos Planos como sinônimo de contemplar a universalidade, a integralidade e a igualdade no acesso aos serviços do SUS. Do mesmo modo, gestão eficiente não aparece como sinônimo de realização de serviço público estatal e de um sistema de princípios integrador, articulador das necessidades de saúde do território e as determinações sociais da saúde e da doença.

Sobre os trabalhadores em saúde, as prioridades seguem tendências políticas e técnicas diferentes. Uma perspectiva que se aproxima dos fundamentos do SUS está nas prioridades quanto à formação, alocação, qualificação, valorização e democratização das relações de trabalho, Plano de Cargos, Carreira e Salários (PCCS) do SUS e respeito ao servidor, que foi mencionada em 6 municípios (Brusque, Chapecó, Criciúma, Mafra, Videira, Itajaí). Em uma perspectiva oposta, outros quatro Planos (Lages, São Miguel do Oeste, Tubarão, Mafra), com objetivos talvez mais tecnicistas e economicistas, se afastam das necessidades coletivas em saúde e da proposta de democratização das relações de trabalho, propõem implantar políticas de remuneração dos profissionais por desempenho, gratificação permanente, elaborar fórum de boas práticas e experiências exitosas de gestão, incentivar por 
meio de premiação e pontuação coletiva as equipes de trabalho.

A relação público-privado parece que está naturalizada na gestão municipal, pois se no diagnóstico pouco se diferenciam os serviços próprios dos serviços privados conveniados e contratados, nas diretrizes para o quadriênio a intenção é aperfeiçoar essa relação por meio da identificação das barreiras que impedem a realização de ações conjuntas das entidades públicas e privadas. Desse modo, propõem aprimoramento da regulação da saúde suplementar, da relação público-privado com as organizações da sociedade e geração de maior racionalidade.

\section{A invisibilidade das Organizações Sociais nos instrumentos de gestão}

Uma pesquisa breve nos sites de busca da internet na qual se colocou apenas a expressão 'Organização Social' e o nome de cada um dos municípios deste estudo, nos deparamos com uma série de achados que estão ausentes nos PMS do quadriênio 20182021. Dos 23 municípios, na época da elaboração dos Planos dois deles estavam com gestão de OS que não foram apresentadas, nem mesmo sua intenção. São José, com o Programa Municipal de Incentivo às Organizações Sociais, desde 2017 tem contrato com o Instituto de Desenvolvimento, Ensino e Assistência à Saúde - IDEAS para fazer a gestão de uma UPA. A cidade de Rio do Sul estava com a UPA administrada pela OS Grupo de Apoio à Medicina Preventiva e à Saúde Pública (Gamp) entre 2016 e 2018, que foi rompido pelo município por entender que não era vantajoso ao erário ${ }^{(17)}$. A intenção de Florianópolis com o Programa "Creche e Saúde Já" aprovado em caráter de urgência logo no início da vigência do Plano não foi revelada. Em seguida celebrou o contrato com o Hospital Psiquiátrico Espírita Mahatma Gandhi para fazer a gestão de uma UPA.

$\mathrm{Na}$ continuidade e por meio de consulta ao site de Leis Municipais ${ }^{(11)}$, em 07 de novembro de 2019 encontramos 10 municípios da nossa pesquisa com leis municipais que instituem o Programa Municipal de Incentivo às Organizações Sociais com base na Lei Federal $n^{\circ}$ 9.637/1998. Essas leis municipais foram aprovadas na última década, conforme segue: 2018 - Florianópolis, Jaraguá do Sul, Mafra e Lages; 2017 - São José e Balneário Camboriú; 2016 - Rio do Sul; 2014 Blumenau e Criciúma; e 2013 - Palhoça.

A pesquisa nos permitiu identificar que dois municípios possuem entidades qualificadas como OS: em Palhoça, o Instituto Corpore de Desenvolvimento Humano foi qualificado em 2017; e em 2019, Criciúma qualificou o Instituto Harmone de Assistência Social, Saúde, Educação e Tecnologia.

As intenções e as práticas dos municípios de entregar a gestão dos serviços de saúde às OS em sua maioria ficaram ausentes dos instrumentos de gestão, afirmação que confirmamos com as notícias de que, em 
Caçador, o Projeto que institui o Programa "Mais Creches e Mais Saúde", e em São Miguel do Oeste, o Projeto de Lei, ambos projetos que tramitavam nas respectivas Câmaras Municipais, foram retirados pelo Executivo devido a pedidos de vista e polêmicas no debate do assunto.

A intenção de expandir a gestão dos serviços públicos para o setor privado ganha uma série de expressões nos municípios. No caso de Joinville, pelo Decreto 28.670/2017 a Administração Pública Municipal estabelece procedimentos de celebração de parcerias por meio de Contratos de Gestão entre as Organizações da Sociedade Civil, Organizações da Sociedade Civil de Interesse Público (OSCIPS) e as Organizações Sociais (OS).

A saúde como impulsionadora do desenvolvimento econômico e da inovação é o projeto do município de Tubarão, por meio de Edital Público de Apoio a Soluções Inovadoras na Área da Saúde, projeto de Hub Saúde, que une a chamada tríplice hélice - setor público, privado e universidades. A justificativa dos gestores é que esse tipo de projeto, semelhante às startups, emerge a partir da identificação de um problema ou de uma "dor", do mercado, dos consumidores ou da vocação econômica para transformar a cidade em um ambiente de inovação e tecnologia. No município, o setor de saúde se destacou pelo potencial instalado, já que o setor de serviços como um todo representa $30 \%$ da arrecadação do Imposto Sobre Serviços (ISS) ${ }^{(18)}$.

\section{Notas finais}

A pesquisa mostrou que os instrumentos de gestão são documentos construídos a muitas mãos e, mesmo com a coordenação geral do setor de planejamento do PMS, os diagnósticos e as prioridades setoriais dos serviços revelam perspectivas que ora se aproximam e ora se afastam dos fundamentos do SUS e da forma de gestão enquanto serviço público estatal. Apenas um município faz uma defesa franca da gestão pública do SUS. Na pesquisa, um município descreve no PMS que tem gestão dos serviços com OS, dois que já cancelaram gestão por prestação inadequada de serviços, dez municípios possuem a lei de incentivo às OS e dois municípios retiraram de pauta a tramitação da lei na Câmara de Vereadores. Supõe-se que haja um ocultamento do funcionamento e das intenções de contratação desse modelo de gestão nos PMS, tendo em vista a necessidade de aprovação no Conselho Municipal de Saúde.

Nos diagnósticos dos PMS os municípios fazem uma descrição indiferenciada da rede pública, da privada prestadora de serviços, da conveniada filantrópica e da particular. Descrevem um conjunto de problemas que envolvem a gestão e parece que vivem sozinhos esse desafio, no entanto dessa forma tornam invisível a relação federativa e a organicidade do Sistema Único de Saúde. A lógica de Sistema Único está se dissipando quando evidenciamos que a gestão 
se vê isolada e não como um membro articulado de uma esfera políticoadministrativa.

No conjunto das prioridades que envolvem a gestão da saúde nos municípios predominam os temas da gestão eficiente na relação com o gasto dos recursos, os resultados dos serviços e a relação com os trabalhadores. No entanto, os temas que envolvem a gestão se dividem, ainda que com sua linguagem genérica e com poucos fundamentos, de um lado, entre a realização dos serviços conforme diretrizes do SUS (serviço público, direito, democratização, necessidades de saúde) e de outro lado, se aproximam da forma de gestão privada, que trata a eficiência (desempenho, produtividade e resultados) por si mesma.

A insuficiência de financiamento é o problema apontado pela maioria dos municípios como o principal desafio da gestão e a narrativa técnico-gerencial da eficiência é referência para a descrição dos problemas e das prioridades. A retórica neoliberal da eficiência vem se impondo na gestão dos serviços do SUS, que parece ter legitimidade e coerência em si mesmo, e faz parecer insensato ou irresponsável qualquer interlocutor que questione suas ideias e, desse modo, instituições como as OS captam e extraem o fundo público.

Com esse resultado evidenciado nos itens anteriores pode-se inferir que o debate e mesmo as práticas de gestão por OS que acontecem nos municípios estão subrepresentados nos PMS. Do mesmo modo, o conteúdo desses instrumentos de gestão, em parte, não nos pareceu coerente com o que se observa aleatoriamente e cotidianamente nos noticiários, nas redes sociais e nos debates sobre a gestão do SUS no estado catarinense. Situação semelhante já tinha sido considerada no estudo dos instrumentos de gestão estadual ${ }^{8}$ (KRÜGER e REIS, 2019).

Ao tratar da gestão do SUS, os PMS não diferenciam a relação público e privado, adotam um raciocínio da eficiência que não preza as necessidades de saúde e nem os fundamentos do SUS (saúde como direito social e coletivo, acesso universal, a ser realizado pelo Estado). Assim, de fato, sedimentam o terreno para que as OS tenham esse 'não lugar' enquanto natureza institucional e fraturam as determinações e articulações políticas e econômicas que envolvem uma política social do tamanho do SUS. 


\section{de-parceria-com-o-terceiro-setor-na-}

\section{Referências}

1. Osório Jaime. O Estado no centro da mundialização. 2. ed. São Paulo: Expressão Popular; 2019.

2. Brasil. Lei $n^{\circ} 9.637$, de 15 de maio de 1998. Dispõe sobre a qualificação de entidades como organizações sociais, a criação do programa nacional de publicização, a extinção dos órgãos e entidades que menciona e a absorção de suas atividades por organizações sociais, e dá outras providências. Brasília (DF). Disponível em: http://www.planalto.gov.br/ccivil_03/leis/ 19637.htm

3. Siqueira CEG, Borges FT. Iventando o reiventado: as Organizações Sociais: de Saúde como modelo de gestão neoliberal de serviços de saúde à Bresser Pereira. In: Sodré F, Bussinger ECA, Bahia L (orgs). Organizações Sociais: agenda política e os custos para o setor público da saúde. São Paulo, Hucitec, 2018; 17-36

4. Brasil. Constituição 1988. Constituição da República Federativa do Brasil. Brasília (DF): Senado; 1988.

5. TCU, Conass, Ibross. Boas práticas, gestão de parceria com o terceiro no setor na saúde. [internet]. Brasília; 2018. [Acesso em 14 nov 2019]. Disponível em https://www.ibross.org.br/livroseminario-2018-boas-praticas-na-gestao- saude/.

6. Krüger TR, Reis C. Organizações sociais e a gestão dos serviços do SUS. Serv. Soc. Soc. 2019 maio/ago [Acesso em 14 nov 2019]; (135):271-289.

DOI http://dx.doi.org/10.1590/0101-6628.178. Disponível em: http://www.scielo.br/scielo.php?script=sc i_abstract\&pid=S0101$\underline{66282019000200271 \& \operatorname{lng}=p t \& n r m=i s \& t}$ $\underline{\operatorname{lng}=\text { pt. } 6 .}$.

7. IBGE. Biblioteca. Perfil dos estados e municípios brasileiros 2018. Disponível em https://biblioteca.ibge.gov.br/ [Acesso em 21 dez 2019].

8. Boletim Política e Saúde. Alta Complexidade. Especial Organizações Sociais na Saúde. Ano III, 6 ed. Brasília; 3 abr 2017.

9. Frente Nacional Contra a Privatização da Saúde. Documento "contra fatos não há argumentos que Sustentem as Organizações Sociais no Brasil”. Relatório Analítico de Prejuízos à Sociedade, aos Trabalhadores e ao Erário por parte das Organizações Sociais (OSs). Jun 2012. [Acesso em 14 nov 2019]. Disponível em https://drive.google.com/file/d/0B3SRQL v1tEAVOE9WUDAtYXlubnc/view. 
10. Santa Catarina. Plano de desenvolvimento de Santa Catarina 2030. Florianópolis; 2018.

11. Portal de leis municipais. [Homepage na internet]. [Acesso em 4 nov 2019]. Disponível em https://leismunicipais.com.br/.

12. Gentili P. Neoliberalismo e educação: manual do usuário. In: Silve TT, Gentili P. (orgs.). Escola S.A.: quem ganha e quem perde no mercado educacional do neoliberalismo. Brasília (DF): CNTE. 1996; 9-49. Disponível em http://static.recantodasletras.com.br/arqui vos/4002523.pdf.

13. Santos IS, Vieira FS. Direito à saúde e austeridade fiscal: o caso brasileiro em perspectiva internacional. Ciênc Saúde Colet [internet]. 2018 [acesso em 20 out 2019] 23(7):2303-2314. Disponível em: http://www.scielo.br/pdf/csc/v23n7/14138123-csc-23-07-2303.pdf.

14. Nogueira M A. As possibilidades da política. São Paulo: Paz e Terra; 1998.

15. Revista IHU On-line. Um Brasil de Bolsonaro será quebrado economicamente, isolado no mundo, exaurido e ensanguentado. Entrevista com Virginia Fontes [Internet].13 out 2018. [Acesso em 16 out 2019]. Disponível em http://www.ihu.unisinos.br/78noticias/583695-um-brasil-de-bolsonarosera-quebrado-economicamente-isolado- $\underline{\text { no-mundo-exaurido-e-ensanguentado- }}$ entrevista-com-virginia-fontes.

16. Brasil. Lei federal $n^{\circ} 13.019$, de 31 de julho de 2014. Estabelece o regime jurídico das parcerias entre a administração pública e as organizações da sociedade civil, em regime de mútua cooperação, [...]; e altera as Leis $n^{\circ}$ s 8.429, de 2 de junho de 1992, e 9.790, de 23 de março de 1999. Brasília (DF). Disponível em

http://www.planalto.gov.br/ccivil_03/leis/ 19637.htm.

17. Diário do Alto Vale. Empresa que administrava UPA é investigada [Internet]. 19 jun 2018. [Acesso em 14 nov 2019]. Disponível em https://www.diarioav.com.br/empresaque-administrava-upa-e-investigada/.

18. Tubarão. Capacitação sobre o edital de apoio à solução na Saúde acontece nesta quarta-feira [Internet]. Tubarão; 04 out 2019. [Acesso em 07 nov 2019]. Disponível em https://www.tubarao.sc.gov.br/noticias/in dex/ver/codMapaItem/16675/codNoticia/ 579181.

\section{Participação dos autores:}

Krüger TR e Bastos COM trabalharam na concepção teórica, coleta de dados, análise estatística e elaboração e redação final do texto;

Krüger TR e Bastos COM trabalharam na concepção teórica, elaboração, análise estatística e redação final do texto; 
Recebido: 29.11.2019

Revisado: 23.12.2019

Aprovado: 13.01.2020 